\title{
THE RESPIRATORY, CIRCULATORY, AND ANALGESIC| EFFECTS OF NALOXONE-NABCOTIC MIXTURES IN ANAESTHETIZED SUBJECTS
}

\author{
Francis F. Foldes, M.d., George M. Davidson, M.B., B.S., \\ Deryck Duncalf, M.B., Ch.B., Shrgeo Kuwabara, M.D., AND \\ EPhraim.S. SikER, M.D.
}

IT WAS PREVIOUSLY REPORTED that $5 \mu \mathrm{g} . / \mathrm{kg}$. intravenously injected naloxone hydrochloride, $\uparrow$ had no significant effect on respiration or circulation. ${ }^{1}$ However, it markedly antagonized the respiratory depressant effects of $20 \mu \mathrm{kg} / \mathrm{kg}$. oxymorphone hydrochloride (Numorphan), $0.66 \mathrm{mg} . / \mathrm{kg}$. alphaprodine hydrochloride (Nisentil), or $2.0 \mathrm{mg} . / \mathrm{kg}$. meperidine hydrochloride (Demerol), administered intravenously, to lightly anaesthetized subjects. The same dose of naloxone also partially antagonized the circulatory effects of $20 \mu \mathrm{g} . / \mathrm{kg}$. oxymorphone. The purpose of the present paper is to compare the respiratory, circulatory, and analgesic effects of $20 \mu \mathrm{g} . / \mathrm{kg}$. oxymorphone, $0.2 \mathrm{mg} . / \mathrm{kg}$. morphine hydrochloride, and 2 mg. $/ \mathrm{kg}$. meperidine administered intravenously alone or together with $5 \mu \mathrm{g} . / \mathrm{kg}$. naloxone to lightly anaesthetized subjects.

\section{Material and Methods}

Sixty female patients scheduled to undergo minor surgical procedures not necessitating the use of muscle relaxants or endotracheal intubation received intramuscularly $100 \mathrm{mg}$. pentobarbital sodium (Nembutal) and 0.3 to $0.4 \mathrm{mg}$. scopolamine hydrobromide 90 and 45 minutes respectively before the start of the experiment. They were divided at random into 6 groups of 10 each. All were lightly anaesthetized with thiopental sodium (Pentothal) and nitrous oxideoxygen according to a technique described elsewhere. ${ }^{2}$ After induction of anaesthesia, control values of pulse rate, blood pressure, respiratory rate, and minute volume were determined. Tidal volumes were calculated from the minute volumes and respiratory rates. Subsequently, the subjects received the following dosages: In group I, $20 \mu \mathrm{g} . / \mathrm{kg}$. oxymorphone alone; in group II, $20 \mu \mathrm{g} . / \mathrm{kg}$; oxymorphone, together with $5 \mu \mathrm{g} . / \mathrm{kg}$. naloxone; in group III, $0.2 \mathrm{mg} . / \mathrm{kg}$. mor phine alone; in group $\mathbb{I V}, 0.2 \mathrm{mg} . / \mathrm{kg}$. morphine, together with $5 \mu \mathrm{g} . / \mathrm{kg}$. naloxone; in group V, $2.0 \mathrm{mg} . / \mathrm{kg}$. meperidine alone; and in group VI, $2.0 \mathrm{mg} . /$ $\mathrm{kg}$. meperidine together with $5 \mu \mathrm{g} . / \mathrm{kg}$. naloxone. Respiratory and circulatory parameters were again recorded at three, six, and ten minutes affter the administration of the various drugs and also at the termination of surgery. In a few cases, the reservoir bag of the anaesthesia machine was replaced by a Sanborn Meta-

${ }^{*}$ Department of Anesthesia, Mercy Hospital, Pittsburgh, Pa. Dr. Foldes is in the Division of Anesthesiology, Montefiore Hospital and Medical Center, 111 E. 210th St., Bronx, New York 10467.

†The salts of the various compounds will only be indicated the first time they appear in the text. 
bolizer and respiratory tracings were made before and after the administration of the various drug combinations.

Ten other female patients (group VII), who in addition received $100 \mathrm{mg}$. meperidine in their premedication, were also given intravenously $20 \mu \mathrm{g} . / \mathrm{kg}$. oxymorphone together with $5 \mu \mathrm{g}$. $/ \mathrm{kg}$. naloxone.

Twelve to fifteen minutes after the administration of the narcotic or narcoticnaloxone mixtures, surgery was started. If the patient reacted to surgical stirnulation (skin incision or dilatation of the cervix), additional doses of thiopental were administered. Similarly, further dosês of thiopental were given throughout surgery as indicated, but no additional doses of narcotics or naloxone were used. The mg./kg. dose of thiopental used for induction of anaesthesia ("sleep-dose") and the mg. $/ \mathrm{kg}$. dose of thiopental required before the patient tolerated surgical stimulation ("initial dose"), as well as the mg./kg. per minute dose of thiopental used throughout anaesthesia, were caculated. The state of consciousness five minutes after discontinuation of the administration of nitrous oxide-oxygen was also observed.

\section{Results}

The respiratory effects of oxymorphone, morphine, and meperidine, administered alone or together with naloxone, are summarized in Tables I, II, and III. It is evident from these tables that the three narcotics tested all caused a significant depression $(\mathrm{p}<0.01$ ) of the respiratory rate and minute volume. With the doses used, the respiratory depressant effect of meperidine was most marked and that of morphine least marked. Maximum depression of the respiratory rate occurred six minutes after the administration of all nareotics. In contrast, the maximum depression of minute volume occurred at three minutes. The depression of tidal volumes was only transient (see Figures 1,2, and 3), and within three minutes they returned near to or rose above control values.
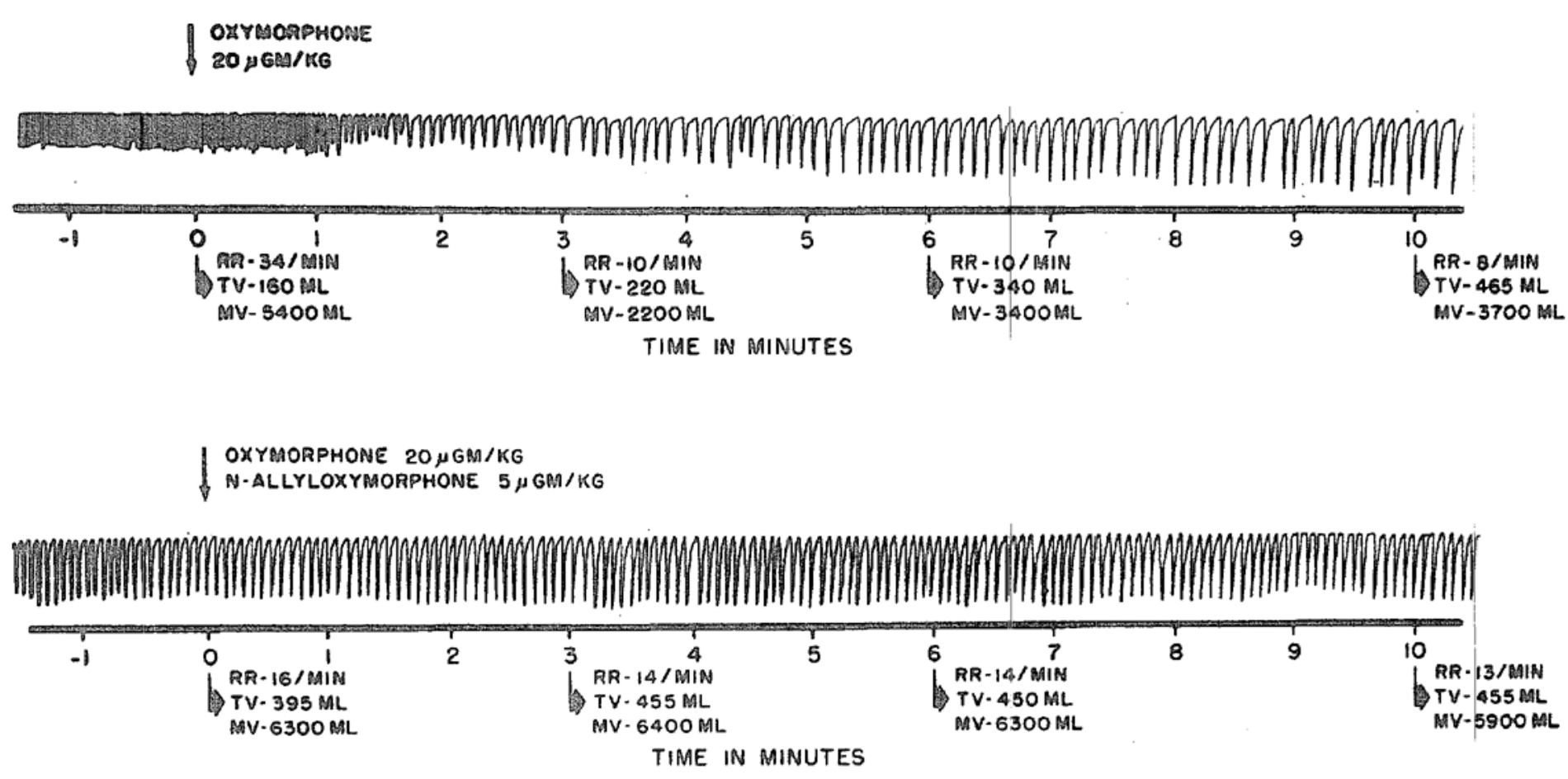

Figure 1. The effect of oxymorphone alone (upper tracing) and oxymorphone combined with naloxone (lower tracing). 

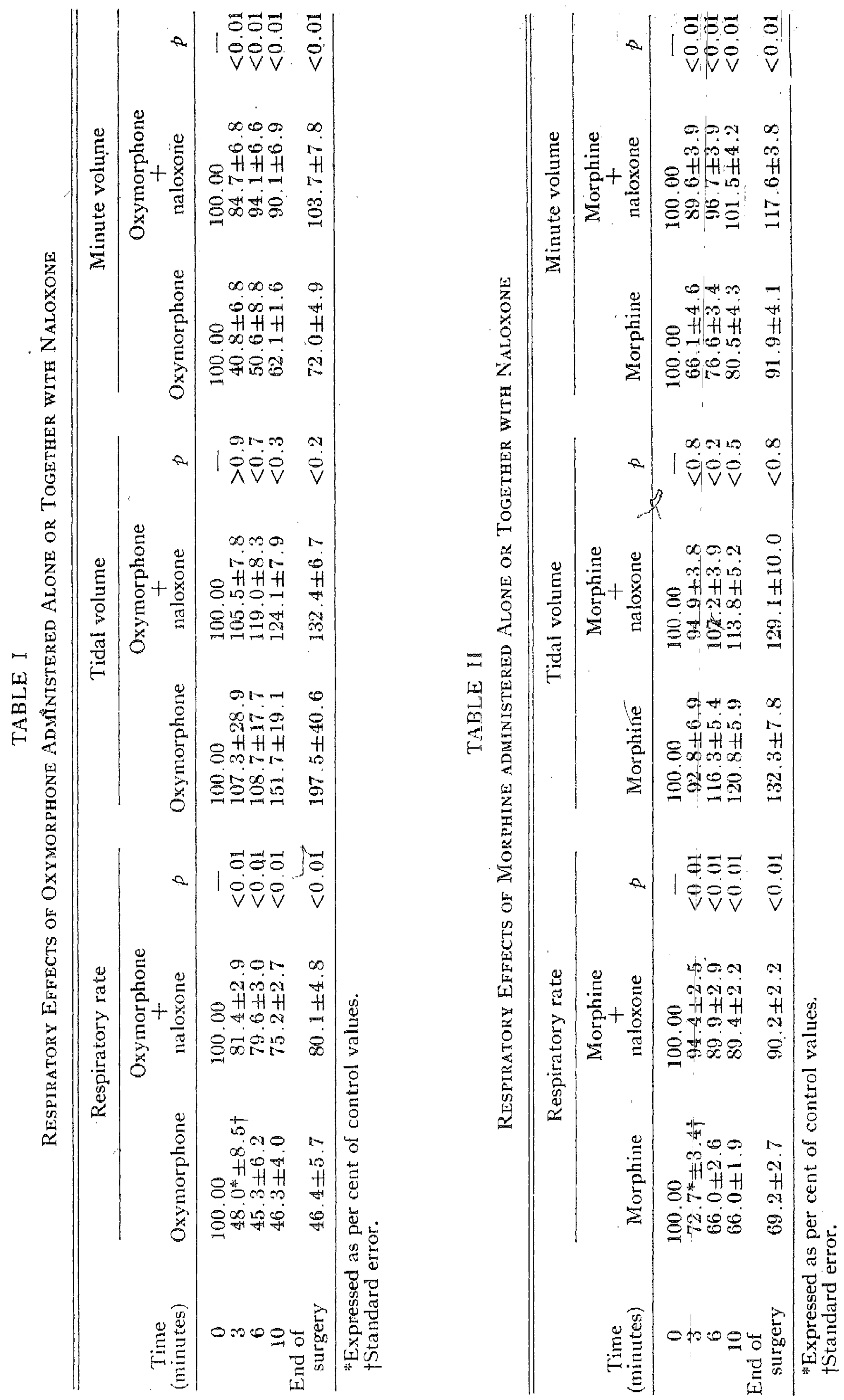


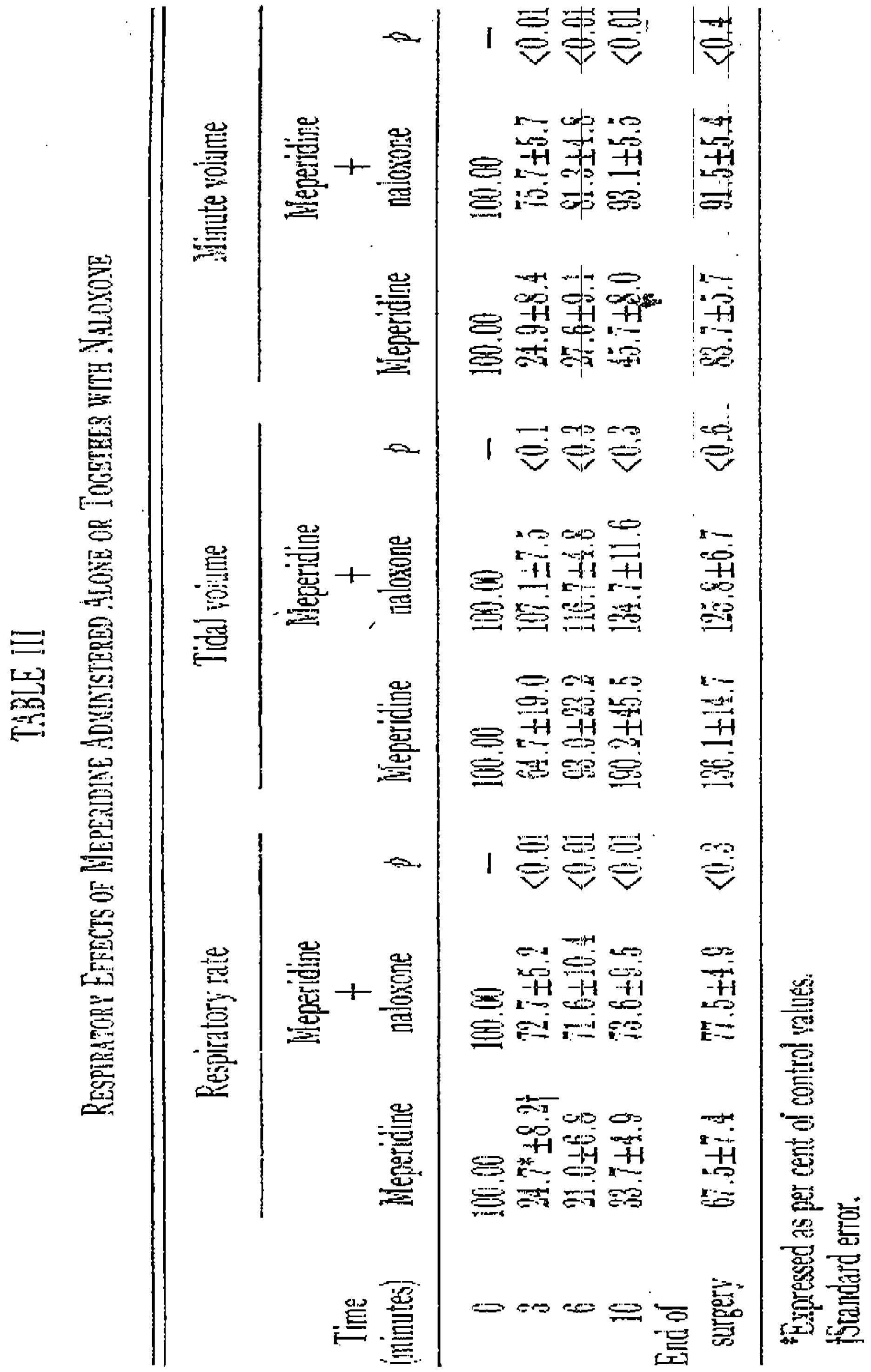




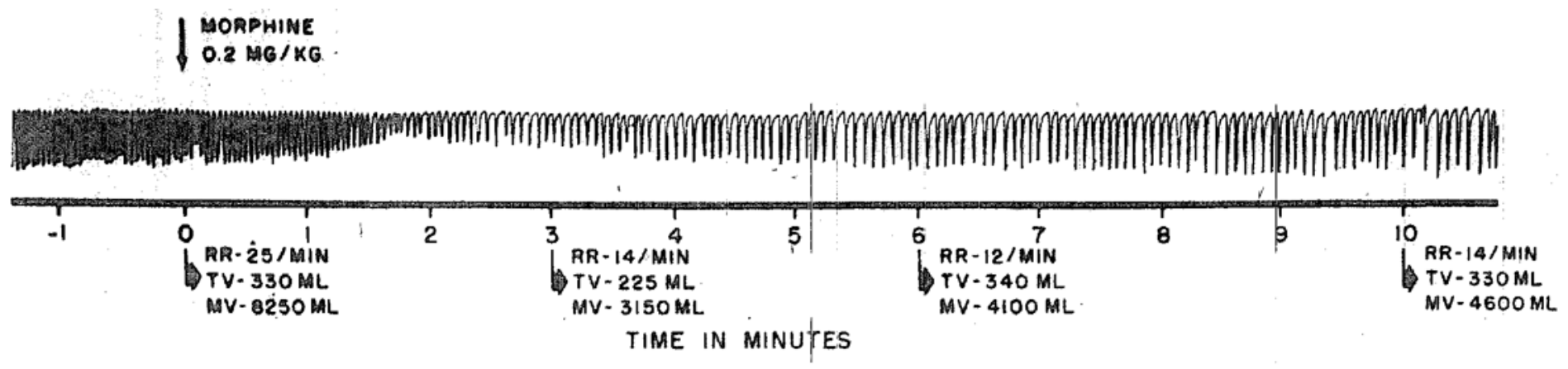

MORPHINE 0.2 MG/KG

N-ALLYLOXYMORPHONE $5 \mu \mathrm{GM} / K G$

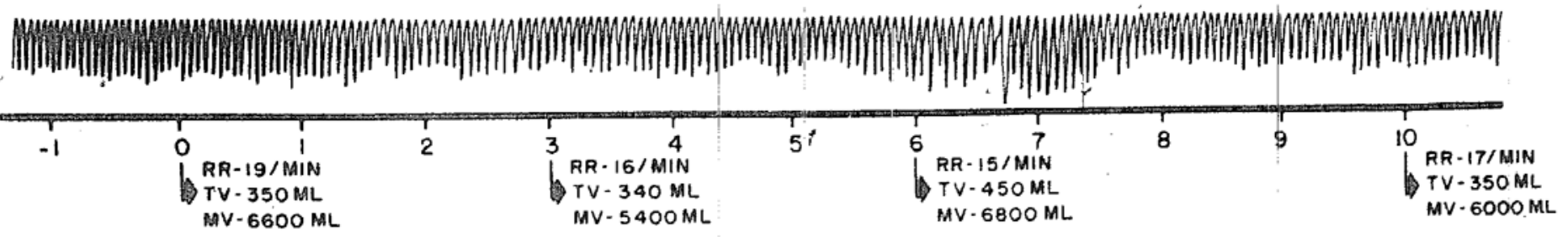

TIME IN MINUTES

FIGURE 2. The effect of morphine alone (upper tracing) and morphine combined with naloxone (lower tracing).

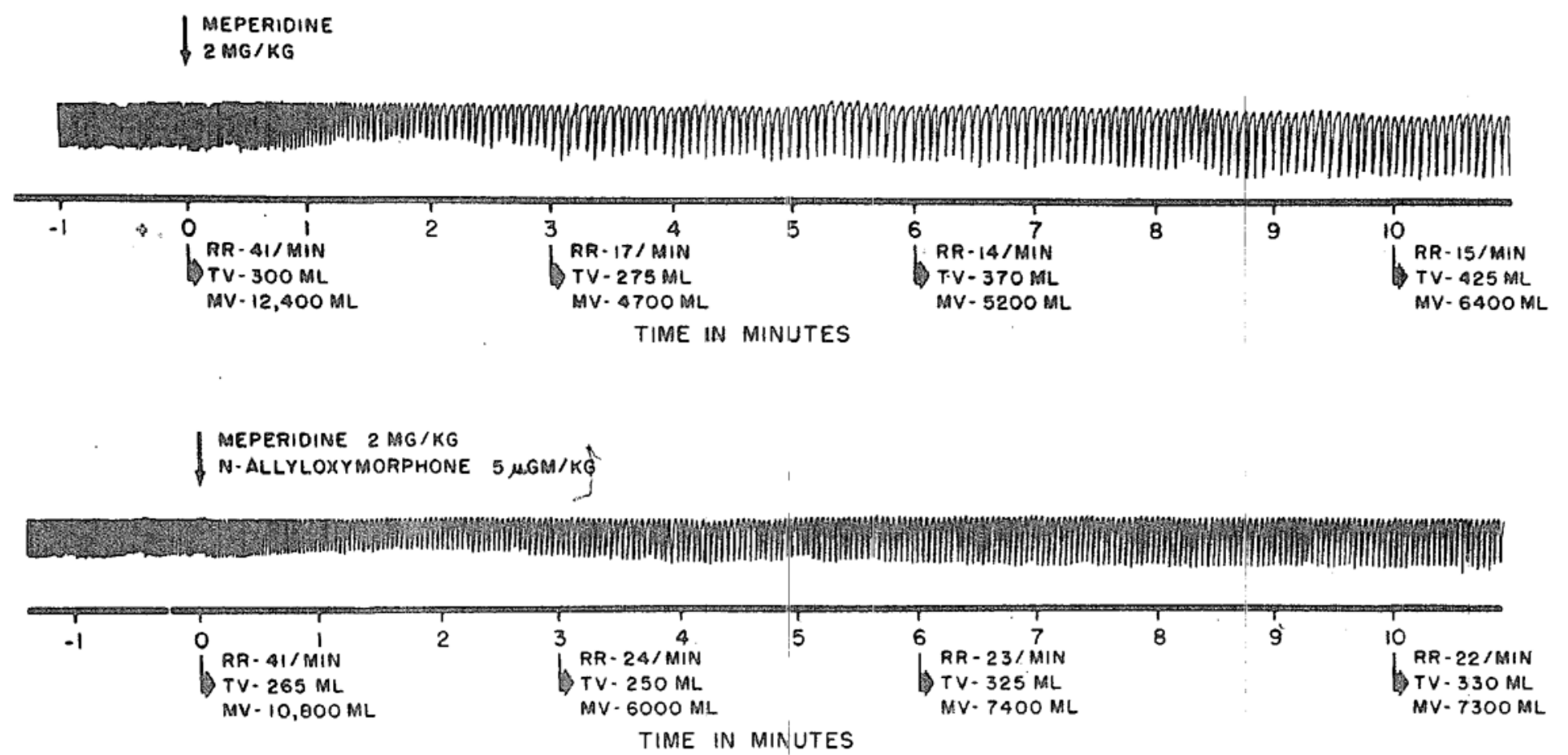

FIGURE 3. The effect of meperidine alone (upper tracing) and meperidine combined with naloxone (lower tracing).

The admixture of $5 \mu \mathrm{g} . / \mathrm{kg}$. naloxone to the three narcotics tested significantly decreased $(p<0.01)$ the depression of the respiratory rate and minute volume, at three, six, and ten minutes after their administration (see Tables I, II, and III, and Figures 1, 2, and 3). The differences observed at these times in the respiratory rate and the minute volume after the administration of narcotics alone, and after the combination of narcotics and naloxone, are highly significant $(p<0.01)$. At the termination of surgery, respiratory rates and minute volurnes were significantly higher $(p<0.01)$ when oxymorphone or morphine was administered together with naloxone than when either was administered alone. However, after the 
administration of meperidine alone or in conjunction with naloxone, there were no significant differences in these parameters at the termination of surgery: This finding is probably due to the relatively short duration of action of meperidine.

The circulatory effects of the narcotics and narcotic antagonist combinations are summarized in Tables IV, V, and VI. Maximum depression of pulse rate occurred at 10 minutes after the administration of oxymorphone, morphine, and meperidine, and amounted to 17,19 , and 10 per cent respectively. Systolic blood pressure was depressed by about 22,14 , and 9 per cent of control with oxymorphone, morphine, and meperidine respectively. Maximum depression of this parameter with the first two drugs occurred at minutes, with meperidine at six minutes. The changes in the diastolic blood pressure paralleled those of the systolic blood pressure. At the termination of surgery, the depression of the pulse rate was about the same as at ten minutes with all three agents. Systolic blood pressure was still depressed at the termination of surgery after oxymorphone and morphine but had returned to control values after meperidine. Diastolic blood pressure at the end of surgery was relatively higher than systolic blood pressure, and after morphine it was actually above its control value. Within the first ten minutes after the administration of narcotics, the admixture of naloxone antagonized bradycardia induced by meperidine, but not that incluced by oxymorphone or morphine. Naloxone had no effect on the depression of systolic blood pressure caused by morphine but it had a tendency to antagonize the hypotensive effects of oxymorphone and meperidine. The same was true for the depression of the diastolic blood pressure caused by these three drugs. At the end of surgery, however, both pulse rates and blood pressures were higher with all three agents, if they had been administered together with naloxone.

There was no statiscally significant difference in $\mathrm{mg} . / \mathrm{kg}$. per minute total dose of thiopental in the six groups premedicated without a narcotic (see Table VII). This finding indicates that, in the dose range employed for the supplementation of light thiopental-nitrous-oxide-oxygen anaesthesia, the three narcotics tested had comparable analgesic effect.

The percentage of patients who reacted to surgical stimulation at the start of surgery was about the same after all three drugs, whether used alone or in combination with naloxone (see Table VIII)

The state of consciousness of the subjects five minutes after the termination of the nitrous-oxide-oxygen administration is also presented in Table VIII. The differences in the state of consciousness at the termination of surgery after the use of oxymorphone and morphine alone or in combination with naloxone are not remarkable. Patients were less reactive after meperidine, used alone or in combination with naloxone, than after the other two agents.

In the ten subjects who were premedicated with 50 to $100 \mathrm{mg}$. meperidine in addition to pentobarbital and scolopamine (group VII) before the intravenous administration of $20 \mu \mathrm{g} . / \mathrm{kg}$. oxymorphone and $5 \mu \mathrm{g} . / \mathrm{kg}$. naloxone, the minute volume, expressed as per cent of control values, was significantly higher $(p<$ 0.05; see Table IX) than in the comparable group (group II) not premedicated with a narcotic (see Table I). The circulatory effects in both these groups were about the same (see Table IV). This apparent discrepancy is probably due to the 

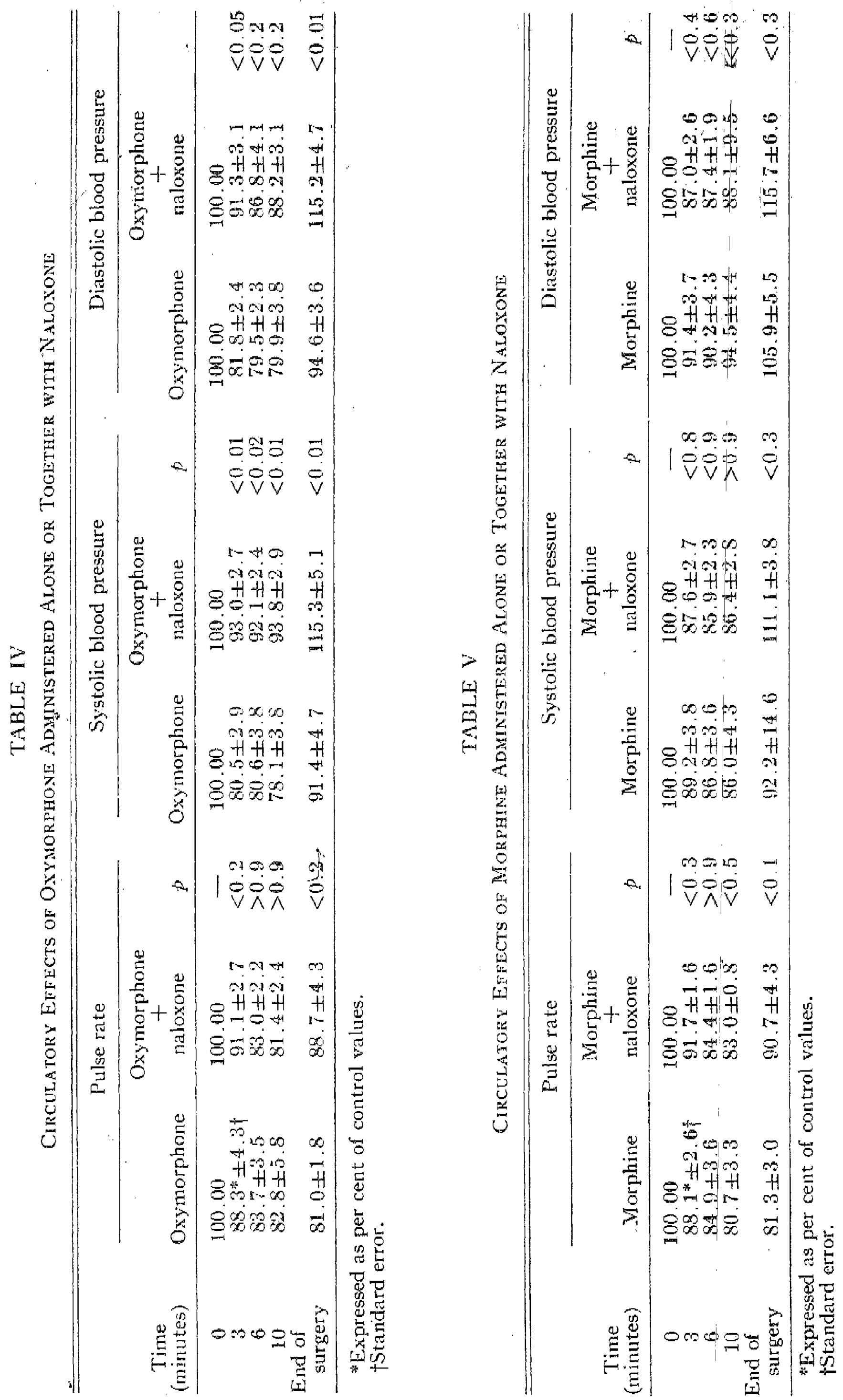


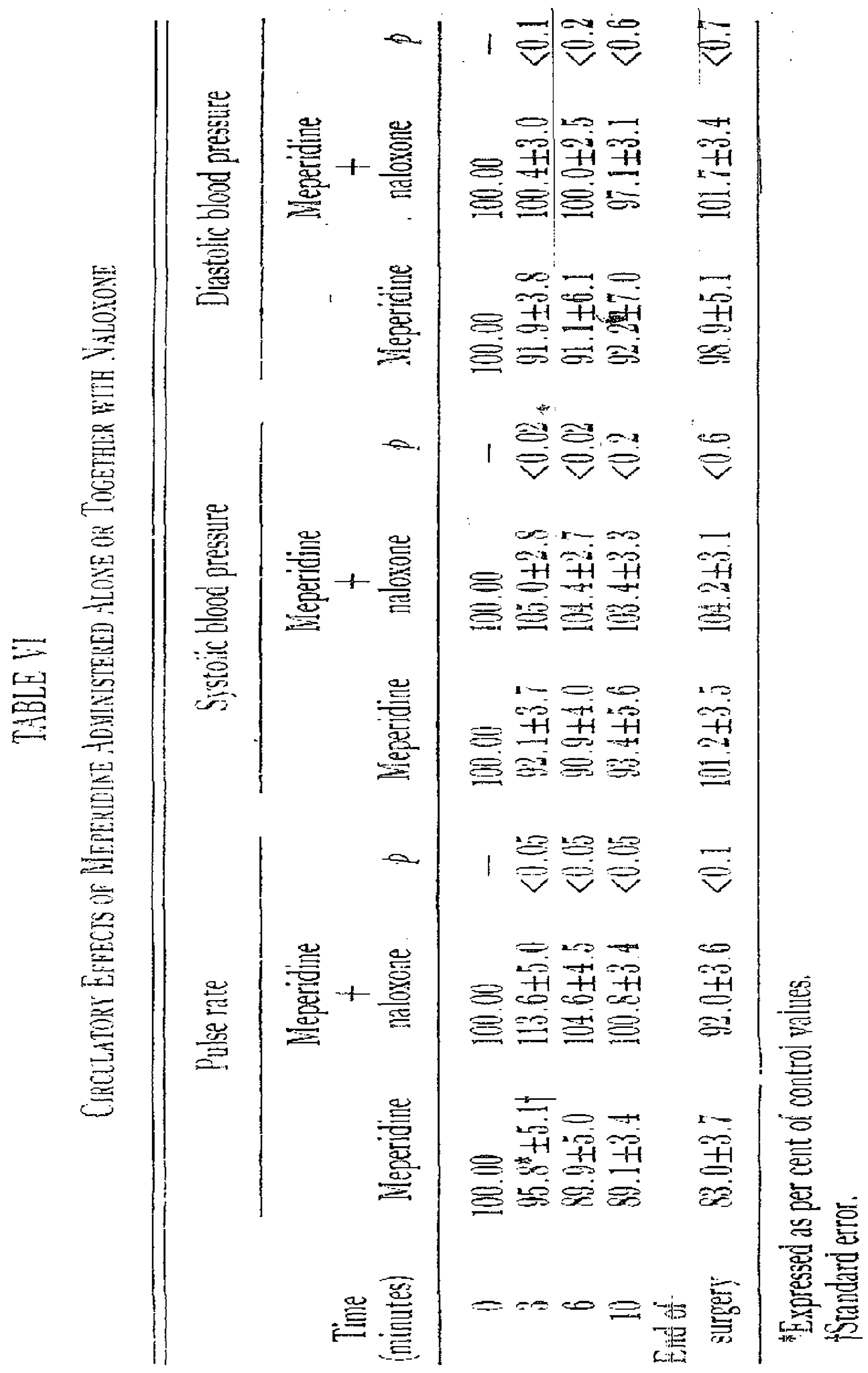


TABLE VII

Thiopental Requirements with Various Narcotic-Narcotic-Antagonist Combinations

\begin{tabular}{llccc}
\hline \hline Group & \multicolumn{1}{c}{ Agents used } & $\begin{array}{c}\text { Sleep-dose } \\
(\mathrm{mg} . / \mathrm{kg} .)\end{array}$ & $\begin{array}{c}\text { Initial dose } \\
(\mathrm{mg} . / \mathrm{kg} .)\end{array}$ & $\begin{array}{c}\text { Total dose } \\
(\mathrm{mg} . / \mathrm{kg} . / \mathrm{min} .)\end{array}$ \\
\hline I & oxymorphone alone & $6.72 \pm 0.57^{*}$ & $7.51 \pm 0.60$ & $0.242 \pm 0.017$ \\
II & oxymorphone + naloxone & $5.61 \pm 0.37$ & $7.57 \pm 0.53$ & $0.192 \pm 0.025$ \\
III & morphine alone & $6.61 \pm 0.45$ & $7.40 \pm 0.40$ & $0.245 \pm 0.020$ \\
IV & morphine + naloxone & $5.80 \pm 0.36$ & $7.94 \pm 0.63$ & $0.238 \pm 0.016$ \\
V & meperidine alone & $6.60 \pm 0.52$ & $7.75 \pm 0.46$ & $0.199 \pm 0.023$ \\
VI & meperidine + naloxone & $6.66 \pm 0.44$ & $7.79 \pm 0.46$ & $0.222 \pm 0.032$ \\
VII & oxymorphone + meperidine & & & \\
& premedication & $4.79 \pm 0.01$ & $6.54 \pm 0.43$ & $0.209 \pm 0.028$ \\
\hline
\end{tabular}

*Standard error.

fact that in group VII, premedicated with meperidine, respiration was already depressed at the outset. The sleep-dose, $4.79 \pm 0.01 \mathrm{mg}$. $/ \mathrm{kg}$. of thippental, was significantly lower $(p<0.05)$ in group VII, premedicated with meperidine, than in the corresponding group II not premedicated with a narcotic. The mg. $/ \mathrm{kg}$. initial dose, $6.54 \pm 0.43$, and the mg. $/ \mathrm{kg}$. per minute total dose, $0.21 \pm 0.03$ of thiopental, however, were similar in group VII to the corresponding values of the other six groups (see Table VII). Furthermore, there was no significant difference either in the number of patients who reacted to surgical stimulation, or in the state of consciousness at the termination of surgery in group VII and the other groups.

\section{Discussion}

The results of this study again demonstrated that narcotic analgesics are powerful respiratory depressants. Although there is considerable difference of opinion with regard to the comparative analgesic potency of the compounds used, it may be reasonably assumed that oxymorphone, $\mathrm{mg}$. for $\mathrm{mg}$., is about ten times as potent as morphine, ${ }^{3,4}$ and that morphine is about ten times as potent as meperidine. On this basis, after intravenous administration of equianalgesic doses, these compounds did not produce the same degree of respiratory depression. The depression of both respiratory rate and minute volume was most marked (about $75 \%$ ) after meperidine, less (about 50 to $60 \%$ after oxymorphone, and least (about 30 to $35 \%$ ) after morphine. The admixture of $5 \mu \mathrm{g} / \mathrm{kg}$. naloxone to these compounds significantly prevented the narcotic-induced respiratory depression of all 3 agents $(\mathrm{p}<0.01)$. Weight for weight, the naloxone-narcotic ratio was 1 to 4,1 to 40 , and 1 to 400 with oxymorphone, morphine, and meperidine respectively. Used in this ratio, the narcotic-induced respiratory depression was reduced from 50 per cent to about 20 per cent with oxymorphone, from 30 per cent to about 10 per cent with morphine, and from 75 per cent to about 30 per cent with meperidine. There was a greater reduction in the control values of the respiratory parameters after the combined administration of meperidine and naloxone than after either oxymorphone or morphine combined with naloxone. This does not necessarily mean, however, that naloxone antagonizes meperidine- 

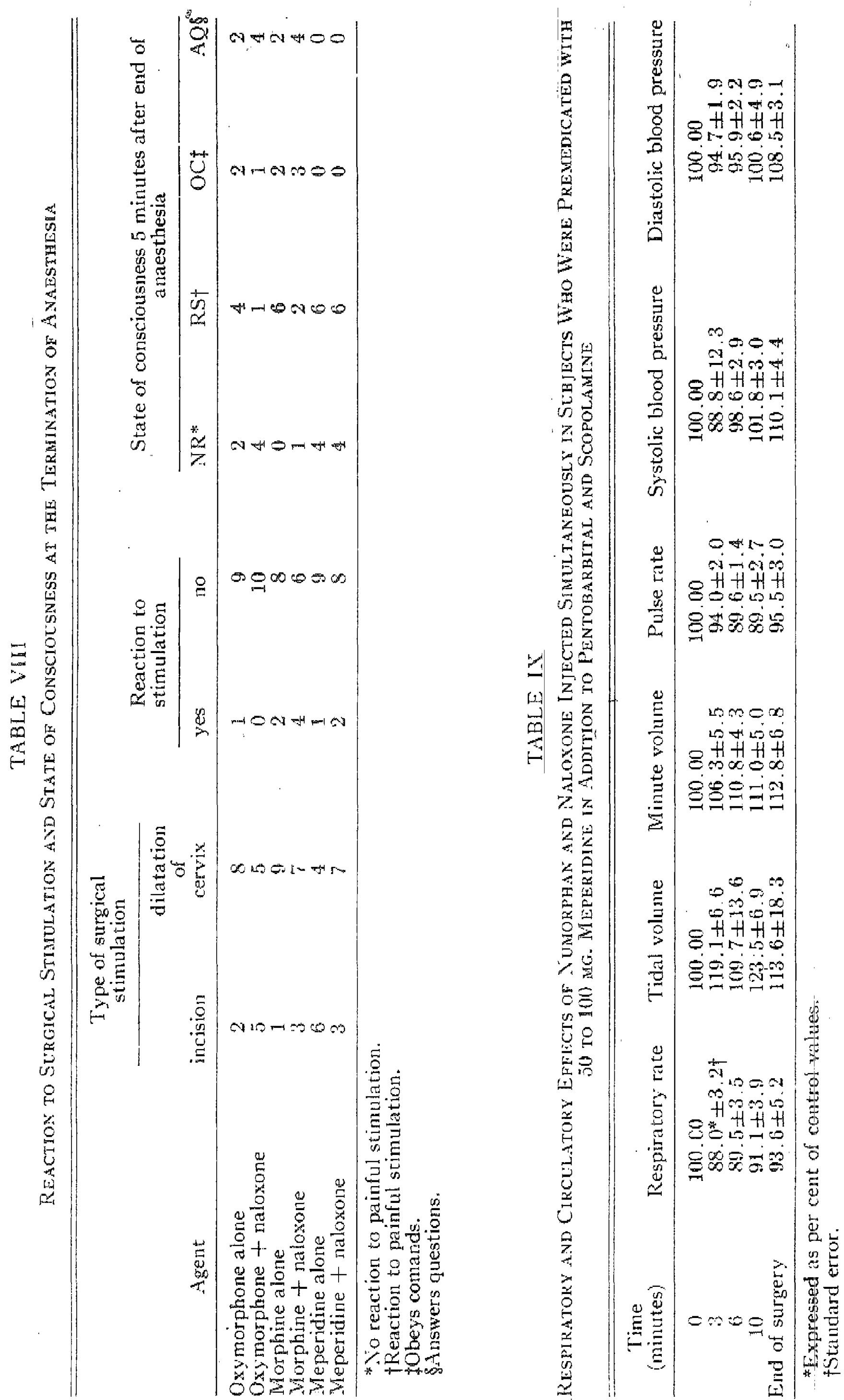
induced respiratory depression less effectively than depression induced by the other two compounds. This is evident when it is considered that when administered alone, meperidine depressed respiration more than the other two narcotics. In other words, after combined intravenous administration the antagonistic effect of naloxone on the respiratory depression caused by each of the three narcotics studied was similar. This observation is in contradistinction to the observations of Sadove et al.,5 who suggested that, after intramuscular administration of equianalgesic doses, naloxone had a greater antagonistic effect on respiratory depression induced by oxymorphone than on that induced by meperidine. The protective effect of naloxone against oxymorphone-induced respiratory depression was about the same whether naloxone was administered together with, or 5 minutes before, the administration of oxymorphone. ${ }^{1}$

The present findings confirm our previous observations, ${ }^{1,6}$ that the antagonistic effect of $5 \mu \mathrm{g} . / \mathrm{kg}$. naloxone on narcotic-induced respiratory depression is greater than that of $20 \mu \mathrm{g} / \mathrm{kg}$. levallorphan. The $5 \mu \mathrm{g} . / \mathrm{kg}$. dose of naloxone that antagonized the respiratory depression caused by oxymorphone, morphine, or meperidine, did not seem to counteract the analgesic effect of oxymorphone or meperidine (see Table VIII). In contrast, the dose of levallorphan, which had similar antagonistic effect on respiratory depression, markedly antagonized the analgesia produced by oxymorphone. ${ }^{6}$

In this study, the circulatory effects of the three narcotics were less marked than their respiratory effects. The antagonistic effect of naloxone on the circulatory depression caused by the narcotics, however, was less uniform than that exerted on the induced respiratory depression. Thus, while naloxone antagonized the bradycardia and hypotension caused by meperidine, it counteracted only the bradycardia but not the hypotension produced by oxymorphone, and did not affect either the bradycardia or the hypotension induced by morphine.

The use of narcotics in premedication is a controversial subject. It has been suggested that because of their adverse circulatory and respiratory effects, unless specifically indicated, narcotics should be omitted from premedication. ${ }^{38}$ Comparison of the respiratory and circulatory parameters in group II, not premedicated with a narcotic, with those in group VII, where 50 to $100 \mathrm{mg}$. meperidine was added to the premedication, indicates that after the induction of thiopental anaesthesia, the omission of narcotics from premedication did not result in better respiratory and circulatory conditions (see Table $\mathrm{X}$ ).

Although the respiratory rate and minute volume were significantly lower $(p<0.05)$ in group VII than in group II, the difference in the alveolar ventilation of the 2 groups was not significant. There was no difference in the circulatory parameters of groups II and VII. It is well established ${ }^{9}$ that occasionally excessive circulatory depression may be encountered after conventional doses of narcotics in sensitive individuals. In normal subjects, however, the circulatory and respiratory effects of the significantly larger doses of thiopental necessary for the induction of anaesthesia in the absence of narcotic premedication, and those of the smaller doses of thiopental required after premedication with meperidine, are similar. 


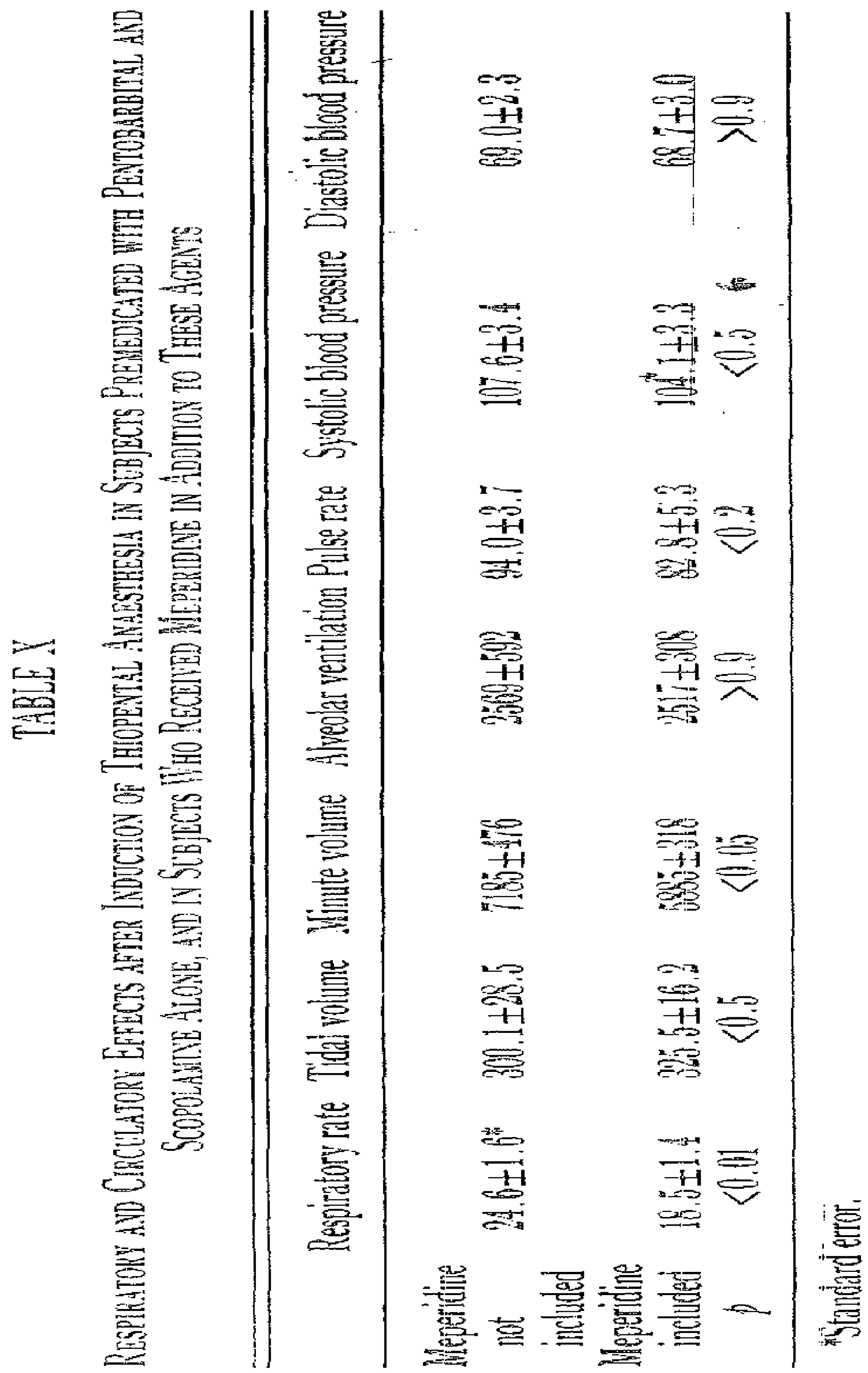


Sixty subjects premedicated with $\mid 100 \mathrm{mg}$. pentobarbital and 0.3 to $0.4 \mathrm{mg}$. scopolamine were lightly anaesthetized with thiopental and nitrous oxide-oxygen, and were divided into six groups of ten persons each. The subjects of each group received intravenously $0.02 \mathrm{mg}$. $/ \mathrm{kg}$. oxymorphone, $0.2 \mathrm{mg}$. $/ \mathrm{kg}$. morphine, or $2 \mathrm{mg} . / \mathrm{kg}$. meperidine, alone or together with $5 \mu \mathrm{g} . / \mathrm{kg}$. naloxone. Pulse rate, blood pressure, respiratory rate, and tidal and minute volume were determined after induction of anaesthesia, three, six, and ten minutes after the administration of the narcotics or the narcotic-naloxone combinations, and at the termination of surgery. When administered alone, the three narcotics caused significant respiratory depression, which was greatest with meperidine and least with morphine. The narcotic-induced bradycardia and hypotension were less marked. The simultaneous administration of naloxone markedly antagonized, but did not completely prevent, the respiratory depression caused by the narcotics. The antagonistic effect of naloxone on the circulatory depression was less marked. The admixture of nalaxone did not seem to antagonize the analgesic potency of the narcotics as measured by their ability to supplement thiopental-nitrousoxide-oxygen anaesthesia. Neither did the admixture of the narcotic antagonist have any effect on the state of consciousness observed five minutes after the termination of anaesthesia.

\section{RÉSUMÉ}

On a administré une anesthésie légère au thiopentone-protoxyde-oxygène à soixante sujets qui avaient reçu en prémédication $100 \mathrm{mg}$. de pentobarbital et 0.3 à $0.4 \mathrm{mg}$. de scopolamine; on les divisa en six groupes de dix. Les sujets de chaque groupe ont reçu en injection intra-veineuse $0.02 \mathrm{mg} . / \mathrm{kg}$. d'oxymorphone, $0.2 \mathrm{mg} . / \mathrm{kg}$. de morphine, ou $2 \mathrm{mg} . / \mathrm{kg}$. cle mépéridine soit seuls, soit additionnés de $5 \mathrm{mg} . / \mathrm{kg}$. de naloxone. Ốn a noté la vitesse du pouls, la pression artérielle, le rythme de la respiration, l'air courant et le volume minute après l'induction, 3,6 , et 10 minutes après l'administration des narcotiques ou des mélanges narcotiques-naloxone, et à la fin de l'opération. Les trois narcotiques, donnés seuls, ont produit une dépression respiratoire importante; la mépéridine a été la plus active dans ce sens, et la morphine la moins active. Le narcotique a produit une bradycardie et l'hypotension était moins marquée. L'admipistration simultanée de naloxone a diminué considérablement la dépression respiratoire causéé par les trois narcotiques, sans toutefois l'empêcher complètement. Les effets préventifs de la naloxone contre la dépression circulatoire ont été moins marqués. L'addition dè naloxone n'a pas semblé nuire à la puissance analgésique des narcotiques, en ce qui concerne leur action de compléter l'anesthésie au thiopentone-protoxyde-oxygène. De plus, l'addition de cet antagoniste des narcotiques n’a eu aucun effet sur le degré de conscience observé cinq minutes après la fin de l'anesthésie.

\section{REFERENCES}

1. Foldes, F. F.; Lunn, J. N. Moore, J; \& Brown, I. M. N-allylnoroxymorphone: A New Potent Narcotic Antagonist. Amer. J. M. Sc. 24t5: 23 (1963). 
2. Fqudes, F. F.; Cerayolo, A. J.; \& Carpenter, S. IL. The Administration of NitrousOxide-Oxygen Anesthesia in Closed Systems. Ann. Surg. 136: 978 (1952).

3. CintibertT, B. J. \& EDdy, N. B. Preanesthetic Medication: Morphine, Anileridine, Oxymorphone, and Placebo. Bull. Drug Addict. Narc. 13: 1 (1961).

4. Keats, A. S. \& Telford, J. Studies of Analgesic Drugs: V. The Comparative Subjective Effects of Oxymorphone and Morphine. Clin. Pharmacol. Therap. I: 703 (1960).

5. Sadove, M. S.; Balagot, R. C.; Hatano, S.; \& Jobgen, E. A. Study of a Narcotic Antagonist-N-allylnoroxymorphone. J.A.M.A. 183: 666 (1963).

6. Foldes, F. F.; LUNN, N. J.; KLEIN, S.; \& SnKER, E. S. The Respiratory Effects of Oxymorphone Administered Alone or in Combination with Levallorphan. Amer. J. M. Sc. 243: 480 (1962).

7. BEECHER, H. K. Preanesthetic Medication. J.A.M.A. 157: 242 (1955).

8. Eckenhoff, J. E. \& Helrich, M. Study of Narcgtics and Sedatives for Use in Preanesthetic Medication. J.A.M.A. 167: 415 (1958).

9. ECKmnoff, J. E. \& OECH, S. R. The Effects of Narcotics and Antagonists upon Respiration and Circulation in Man. Clin. Pharmacol. Therap. 1: 483 (1960). 